\title{
المتلازمات اللفظية (collocating words) تعريفها وأنواعها وتكوينها في اللغة العربية
}

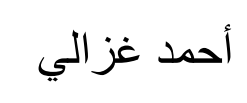

\author{
الملخص
}

ومن الملامح المميزة للغة هي: الطبيعة الصوتية للغة والطبيعة

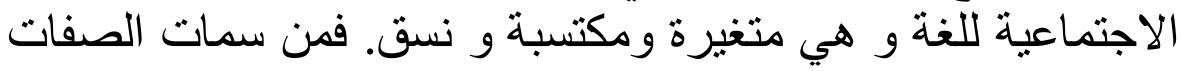

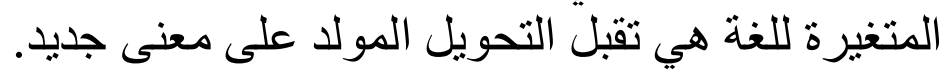

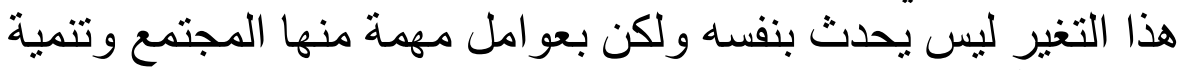

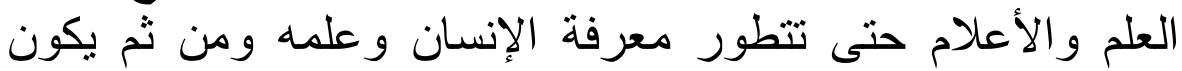

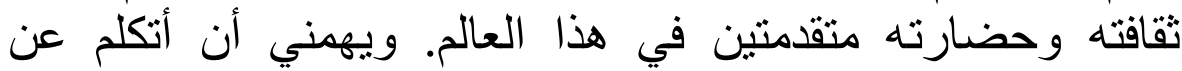

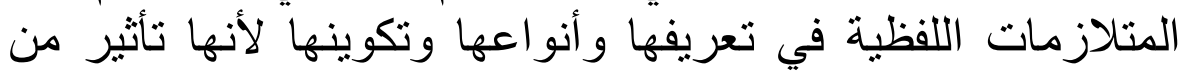
ذلك التغير. و أهم هذا الحديث أنها وحدة لغوية اسمية أو فعلية، مكونة التهاتئ من كلمتين أو أكثر من ارتباطها ينشأ معنى جديد يختلف كليا.

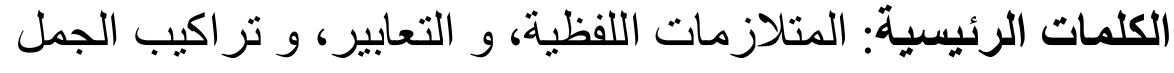

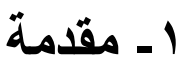

إن اللغة عنصر أساسي في الحياة الاجتماعية راقية كانت أو بدائية.

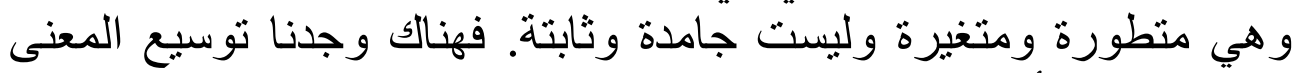

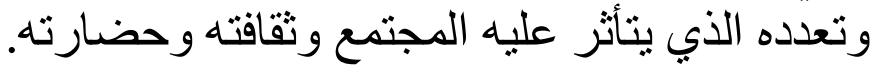

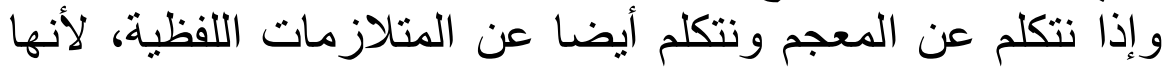

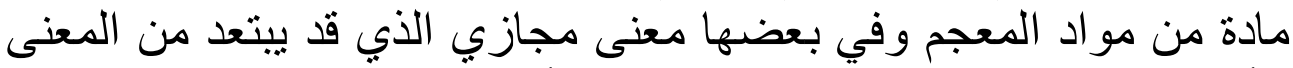

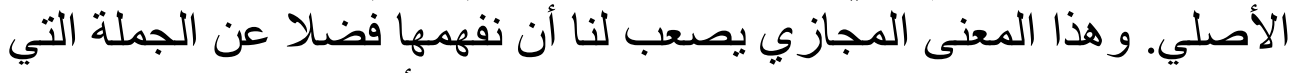

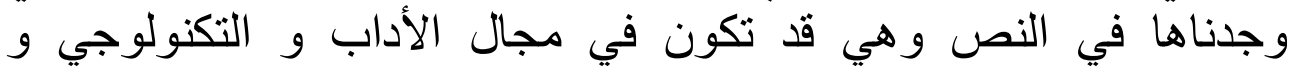
الصحافة و غير ها. ففي هذا المجال سيبحث الكاتب عن المتلازمات اللفظية وتعريفها و أنو اعها و تيكوينها.

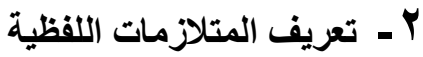

يشير مصطلح " المتلازمات اللفظية " إلى كلمة يقترن استخدامها في اللغة بكلمة أو كلمات أخرى وقد يطلق عليها البعض أسماء أخرى مثل 
المصاحبة اللفظية أوالمتصاحبات اللفظية أو المتواردات أو المقترنات أو

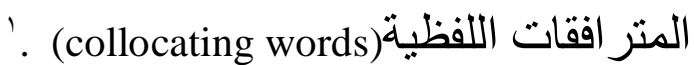

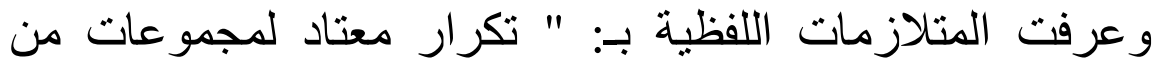

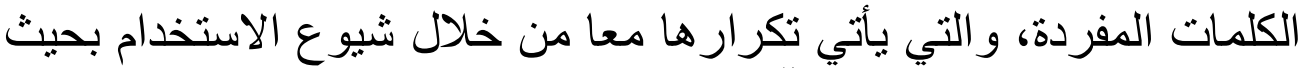

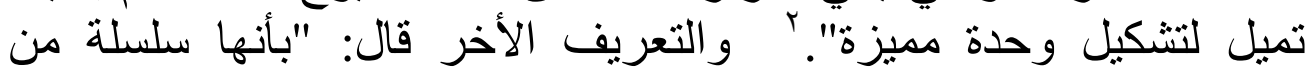

الكتوقع". أو المصطلحات التي تظهر في كثير من الأحيان أكثر من فن

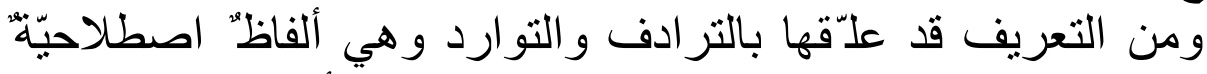

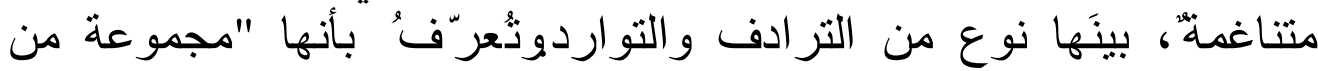

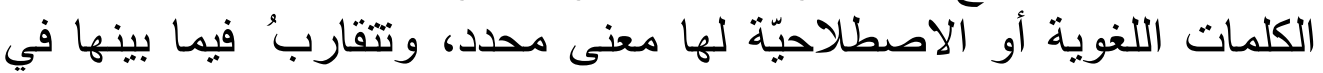

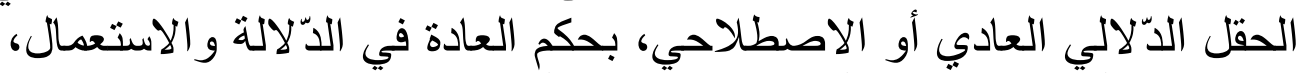

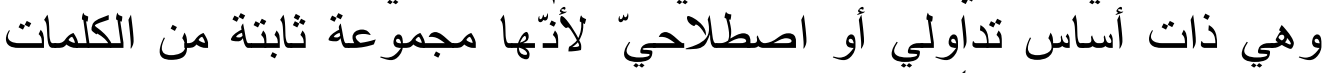
تحمل معنى خاصا.

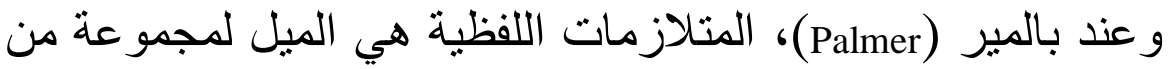

العناصر المعجمية التي تظهر في السياق اللغوي. ويتعلق بهذا كان

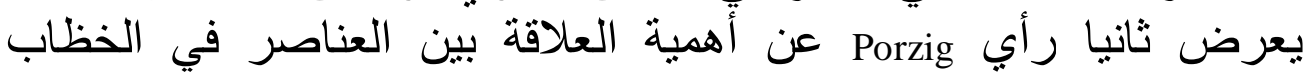
Firth (العلاقة سنتغماتيك Sintagmatik ) و هذا المتلازمات اللفظية عند فيرثة

$$
\text { هي جزء من معنى الكلمة. }
$$

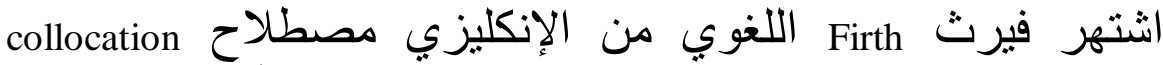

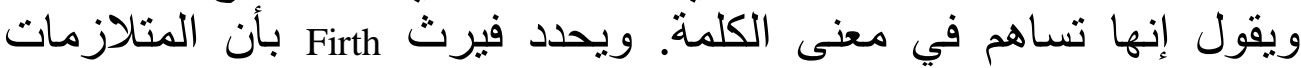

اللفظية هي: فكرة مجردة على المستوى Sintagmatik و لا تركز مباثُرة بفكرة

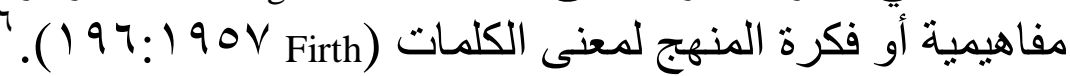

"Meaning by collocation is an abstraction at the syntagmatic level and is not directly concerned with the conceptual or idea approach to the meaning of words." ${ }^{\mathrm{r}}$

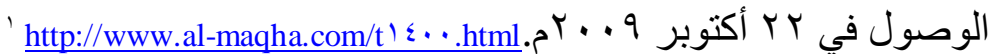

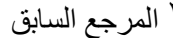

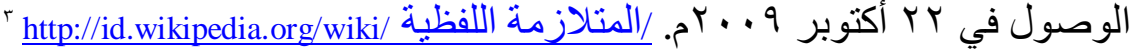

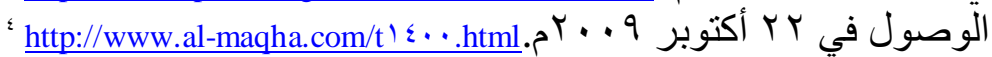

- Maretta Kartika Sari, Kesalahan Unsur Leksikal (Jakarta: FIB UI, r . . 9)

'Firth, J.R, Papers In Linguistics (London: Oxford University Press, 19 $19 \varepsilon_{-} 1901$ )
}

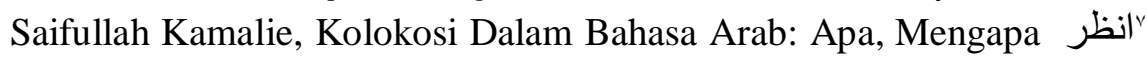
قدمت المقالة في المؤتمر الدولي في اللغة العربية بموضوع: اللغة 


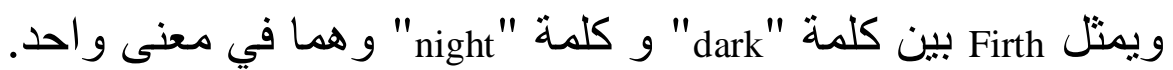

وعرف أيضا Sinclair ـ الذي تلمدّ مع "Firth في جامعة لندن- وقدة وقال:

"Collocation is the occurrence of two or more words within a short space of each other in a text."

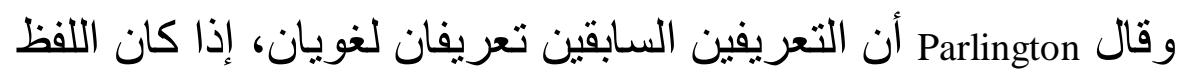

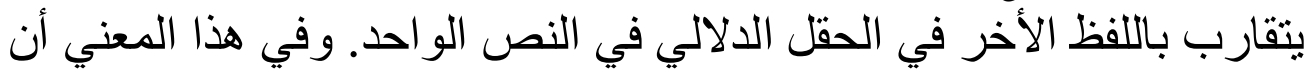

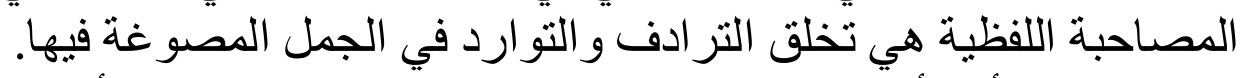

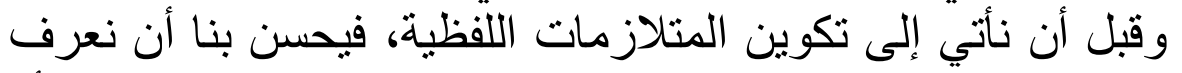

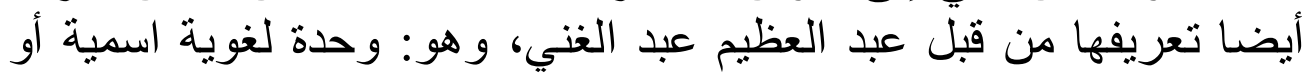

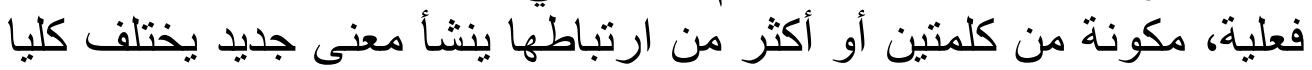

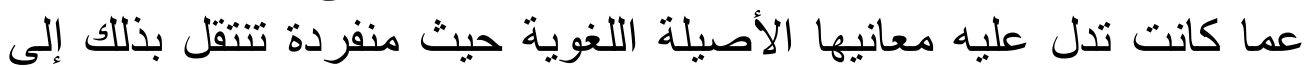

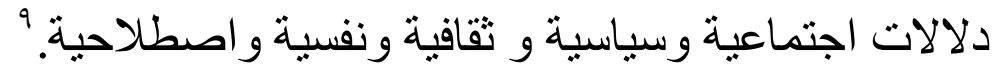
يثنير هذا التعريف إلى طريقة تكوين المتلازمات اللفظية بأنها من

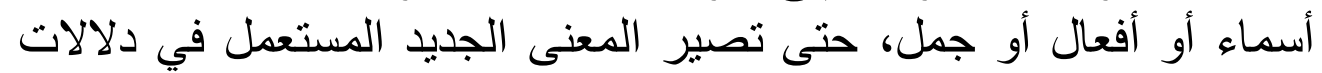
اجتماعية وسياسية و ثقافية ونفية ونية و واصطلاحية.

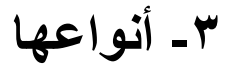

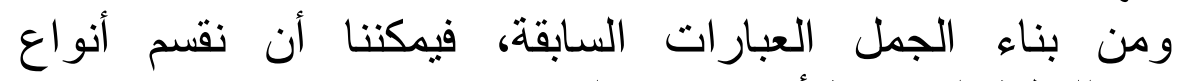

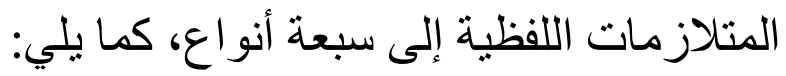
ا ـ المسكو كات التامة: kolokasi penuh

التي تتكون من وحدة لغوية ويظهر منها معنى جديد يختلف من معناه

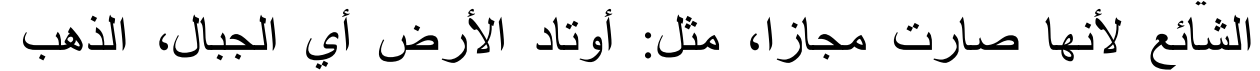

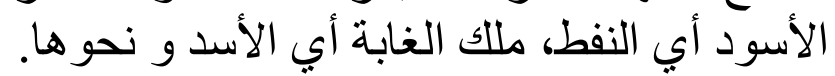
ب ـ التعابير السياقية: ungkapan kontekstual

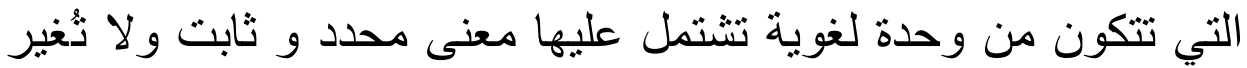

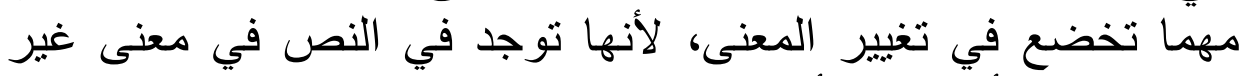

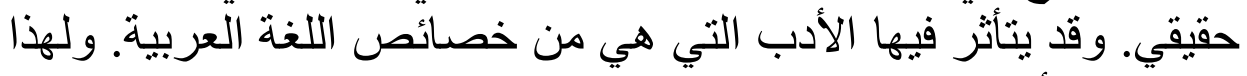

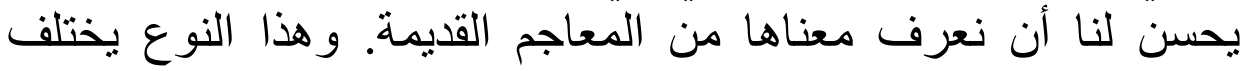

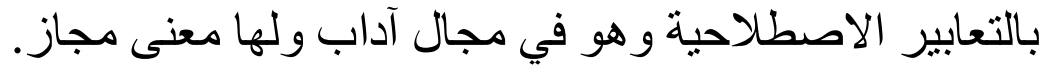

العربية و الأدب الإسلامي مناهجه وتطويره، الذي أقامه نقابة مدرسي اللغة العربية

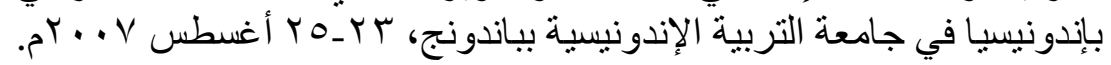

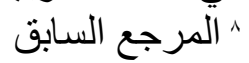

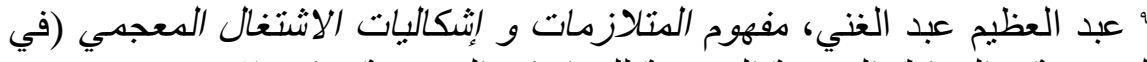

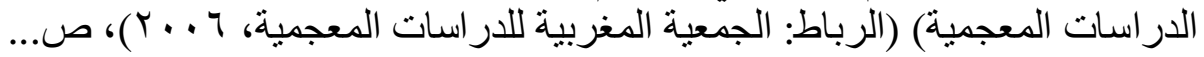


الأمثلة في هذا النوع: ضرب آباط الأمور، فمعناها الأصل هو memukul ketiak perkara أثرا بعد عين: jangan mencari bekas setelah mata، المقصود jangan mencari لاهنا bekas sesuatu ketika bendanya telah tiada 'nasi telah menjadi bubur'. r ـ التعابير الاصطلاحية: 'idiom

التي تتكون من كلمنين أو أكثر حتى تصير وحدة اصطلاحية ومعناها

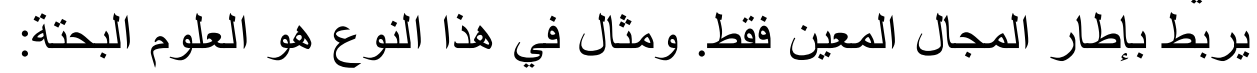
ilmu murni الأنثروبولوجية: antropologi.

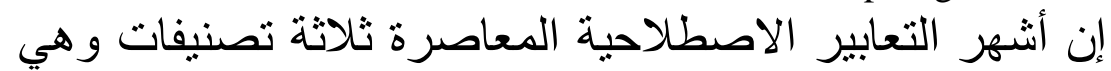
التقسيمات النحوية، و العلاقات الأسلوبية و المجازية، ومصادر الإداتية التعابير

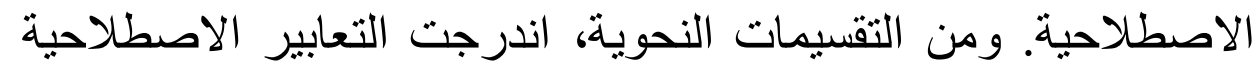

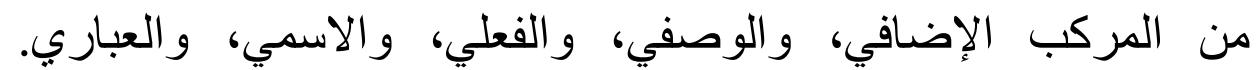

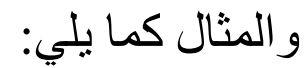
- المركب الإضافي: آخر العنقود، ابن الحلال، أعمى القلب، ونسيج

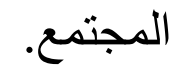
ـ المركب الوصفي: اليد العليا، كلام فارغ، السوق السوداء، و ابتسامة

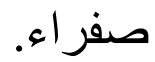
ـ المركب الفعلي: ذحبه بسكين بارد، يدفن الرؤوس في الرمال، أعطى

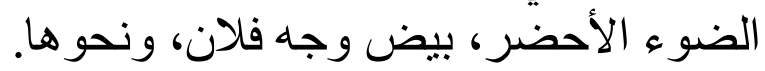

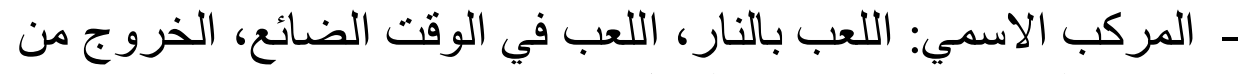
عنق الزجاجة، نائم في العسل، زوبعة في فنجان، وفلان نفسه ـ المركب العباري: بالفم المليان، على كف عفربيت، بأم أذني، و بدم

وأما العلاقات الأسلوبية والمجازية بين عناصر التعابير

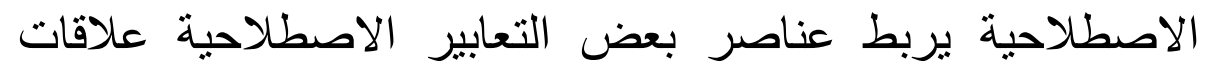

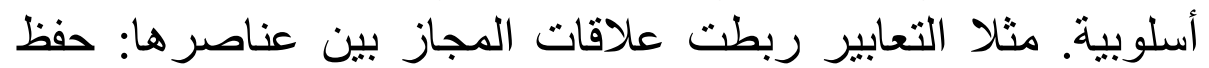

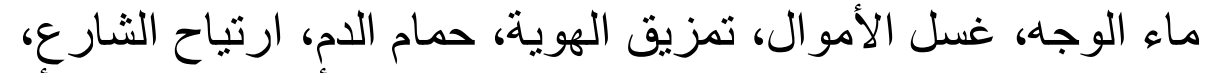

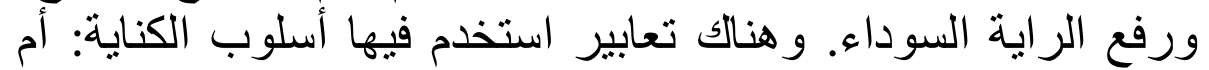

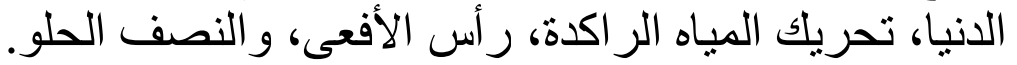


وأما مصادر التعابير الاصطلاحية فهي من تعابير مقترضة

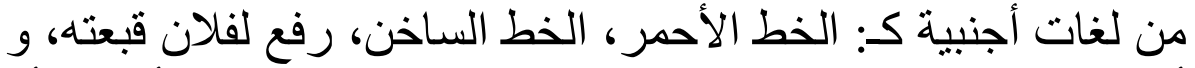

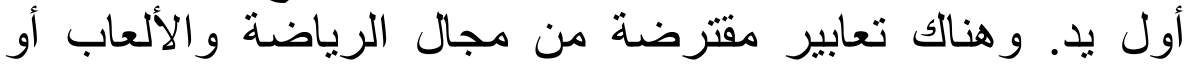

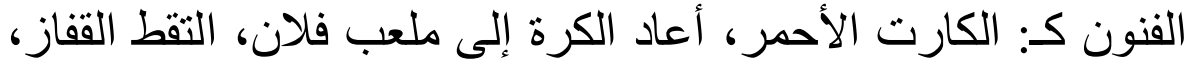

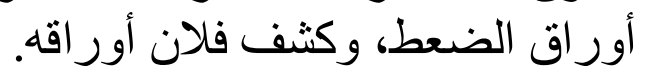

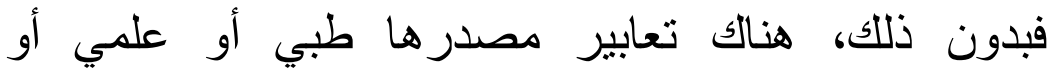
اقتصادي مثلا غسل المخ، القمر الصناعي، و النزيف العلمي. وتعابير

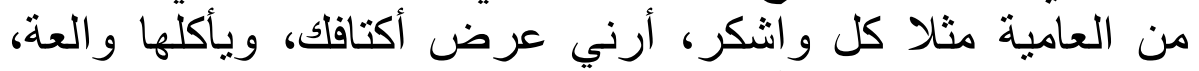

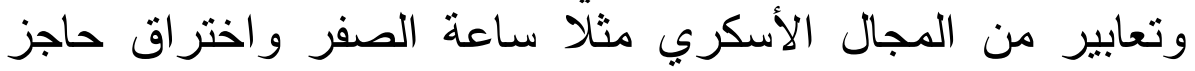

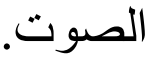

ع ـ تعابير أسماء الهيئات ومختصر اتها: singkatannya ومثال في هذا النوع هو الجامعة العربية: Liga Arab، هيئة الأمم المتحدة: Persatuan Bangsa-bangsa الألكسول The Arab League Educational Cultural and Scientific Organization (ALECSO) ، المنظمة الإسلامية للتربية والعلوم و الثقافة:

الإكسيسكو Islamic Educational Scientific and Cultural Organization

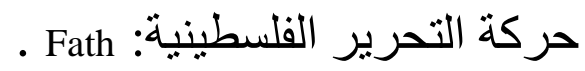

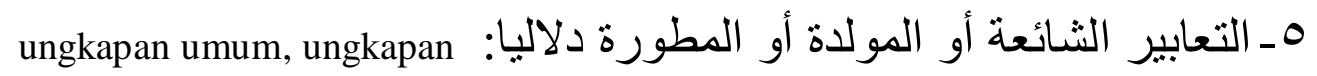
post-classical, ungkapan yang dikembangkan secara semantik وهذا النوع كثير في استعماله، وهو تتألف من كلمتين أو أكثر، مثل:

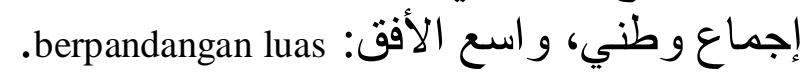
ا ـ التعابير الإتباعية: ungkapan itbaiyyah

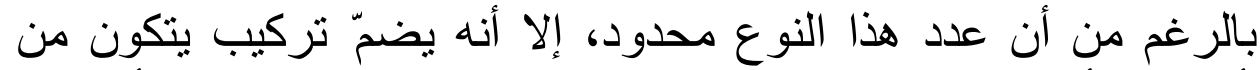

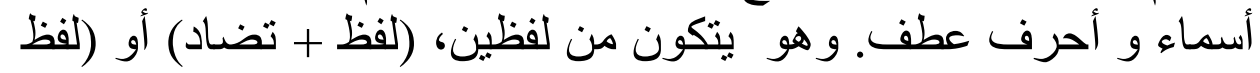

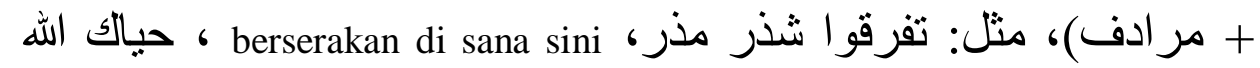

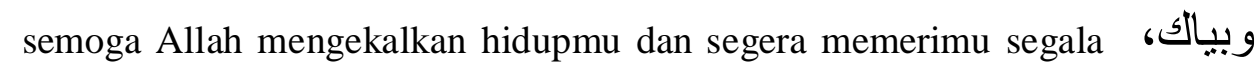
تركئب apa yang kamu kehendaki dan menempatkanmu di temapt yang baik تركيب آخر: إربا إربا، (kecil-kecil) sepotong-sepotong ، السراء و الضر اء، masa senang dan susah: ، حسب إربا، ونسب، . keturunan ungkapan pribahasa - تعابير الأمثال السائرة V 
ومثال في هذا النوع: لكل جواد كبوة أو كل صارم نبوة،

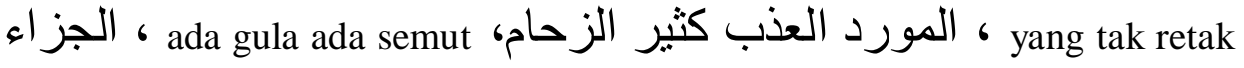

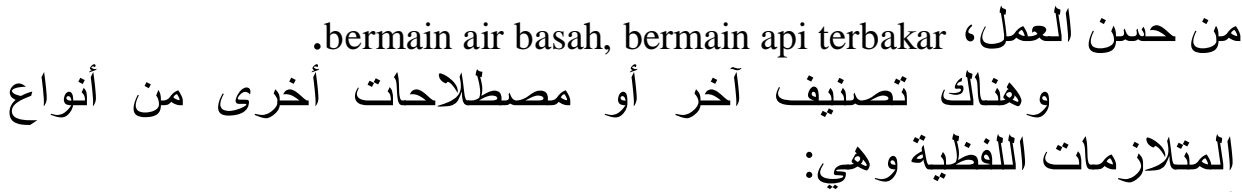

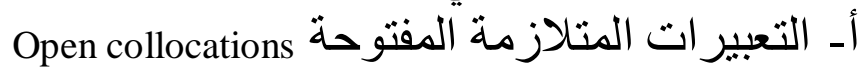

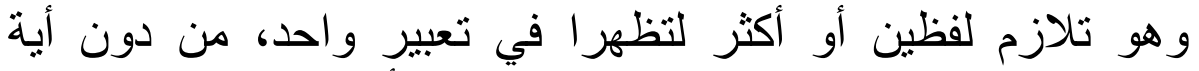

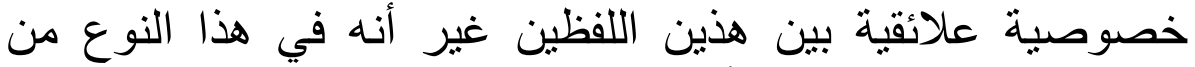

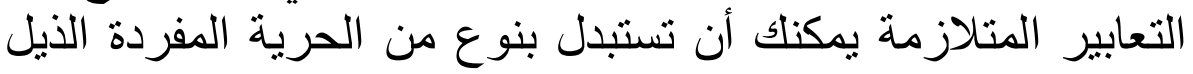

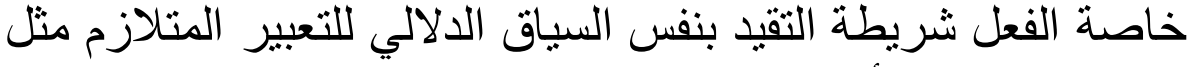

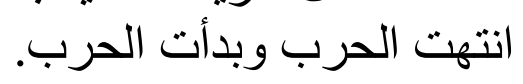

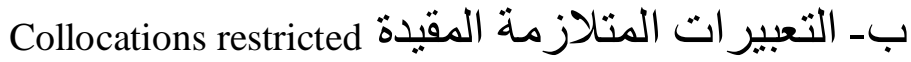

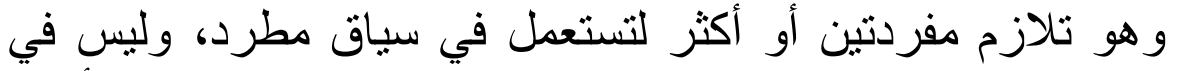

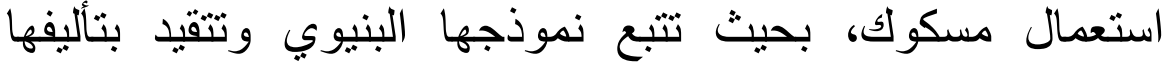
الاستبدالي نحوا ودلالة وتداولا نحو: حرب ضارِّة فيكة جريمة نكراء، أحرز تقدما، وخسار ات جسمية.

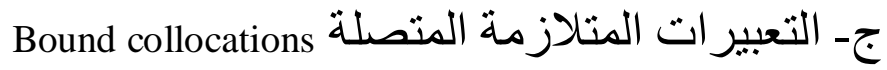

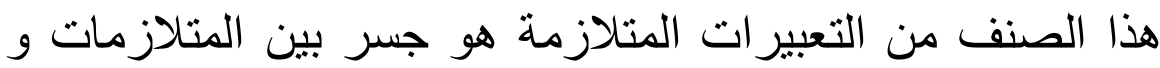

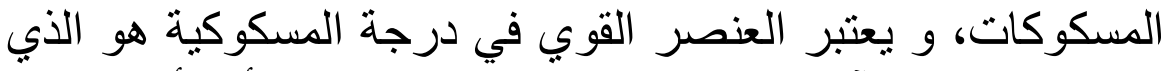

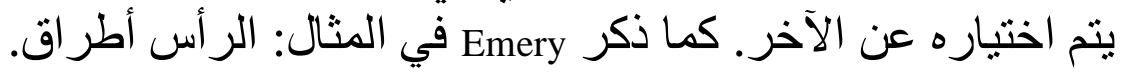

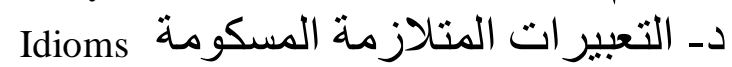

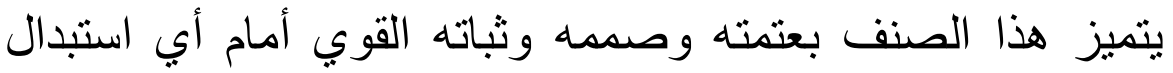

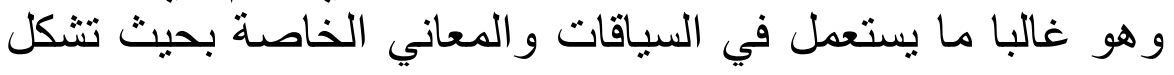

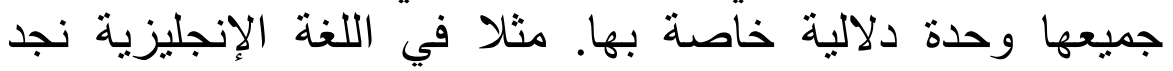

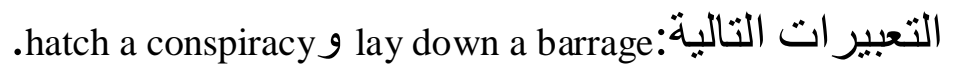

في اللغة العربية لفظ: heavy أثنار محمد حلمي هليل إلى أن فئل

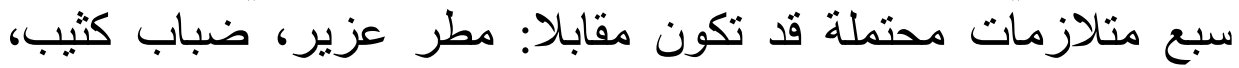

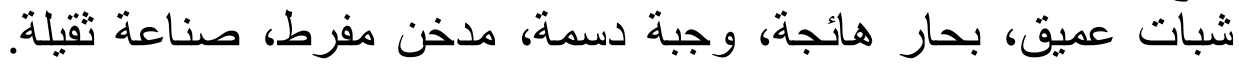

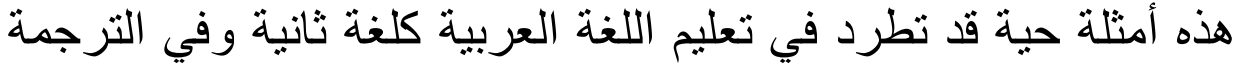
من اللغة الإندونيسية الى اللغة العزية العربية. ويمكن نتبع هذه الظاهرة - المتلازمات اللفظية (Collocation) ـــي القصص النبوي من خلال اطر اد مجمو عة من المفردات في شكل 
ثنائي يشي بالاجتماع و التزر ابط المعنوي مثل (أدركه الموت) و (كابر

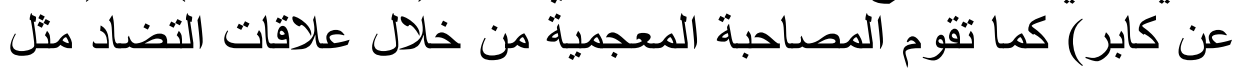

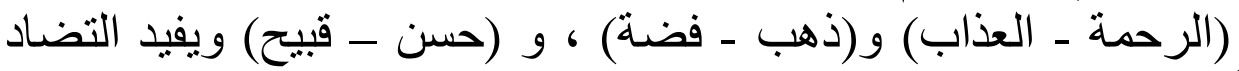

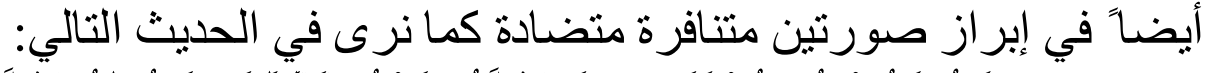

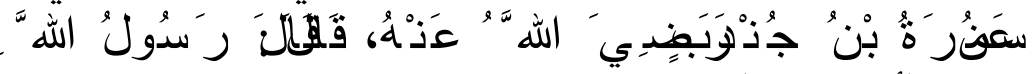

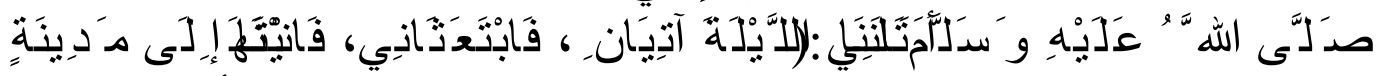

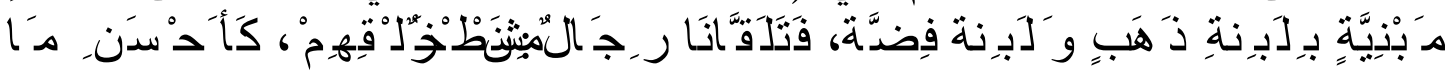

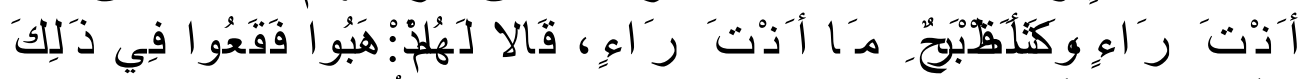

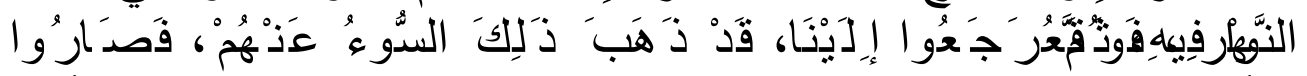

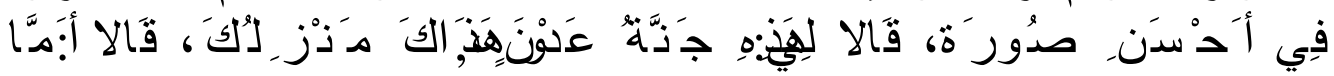

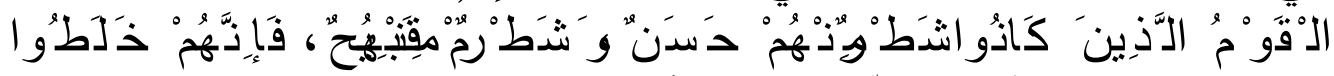

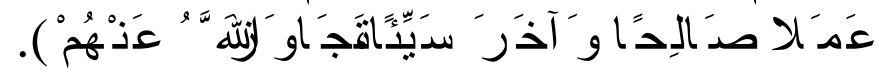
ـ - تكوينها

بناء المتلازمات اللفظية في اللغة العربية ينكون من تركيب الاسم،

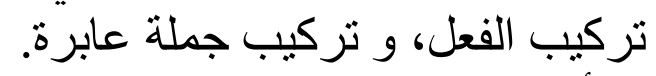

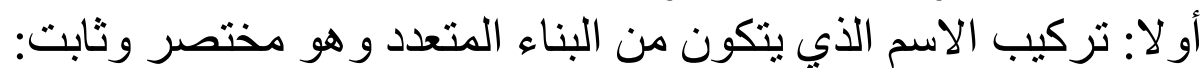

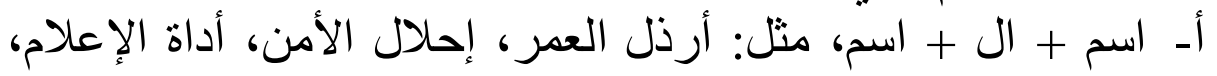
وغير ذلك.

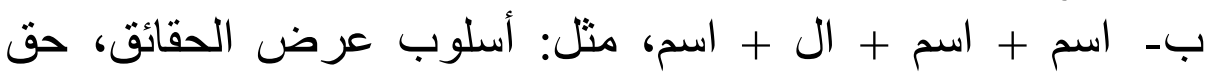
تقرير المصير، إطلاق سر اح السجين ونحوها.

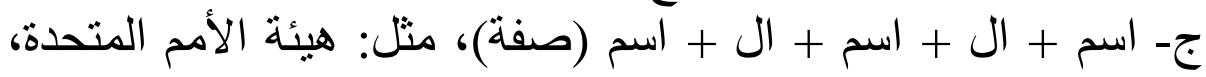
منظمة الصحة العالمية، إعداد الرسوم المتحركة.

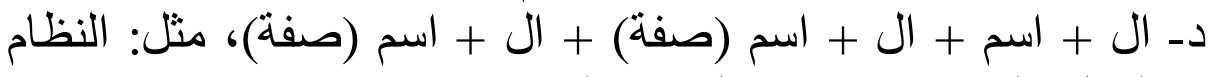

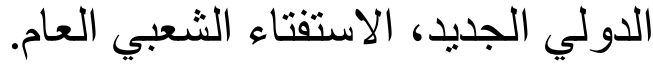

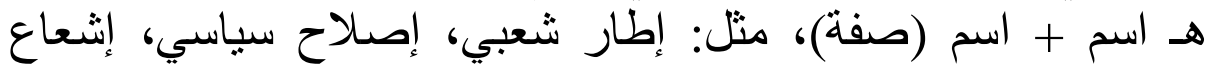

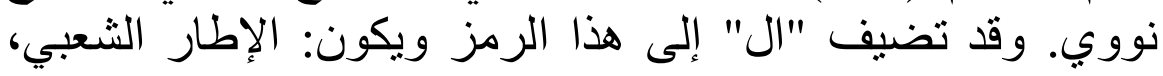

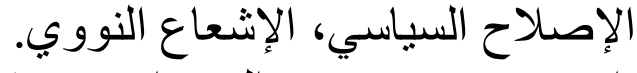

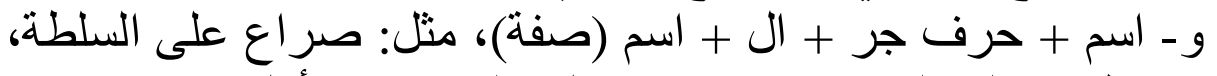
انطو اء على النفس. وقد تضيف "ال الت" إلى الاسم الأول.

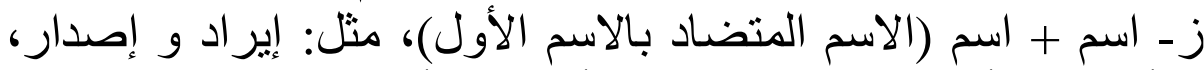
أبيض و أسو اد، ذهاب و إياب، أفراح و أتراح. وقد تضيف "الإل الإل

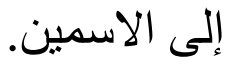


ح- اسم + اسم (الاسم المرادف بالاسم الأول)، مثل: آراء و أفكار، إسارك

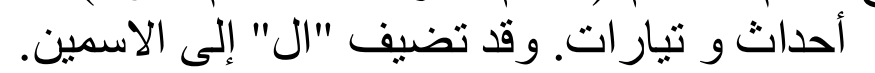

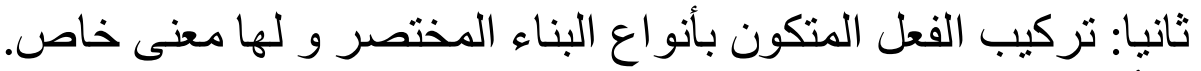

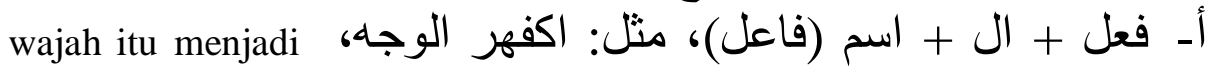

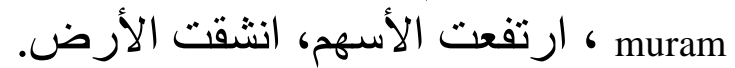

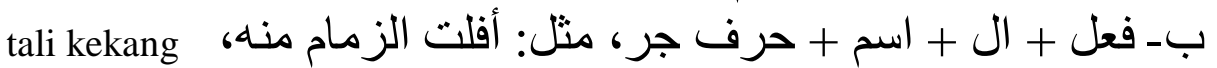
terlepas darinya.

$$
\text { ج- فعل + ال + اسم، مثل: أحيا الليل. }
$$

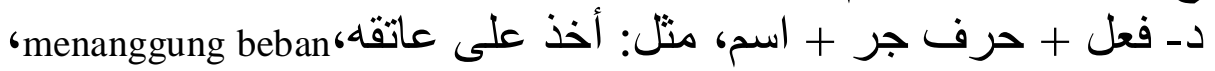

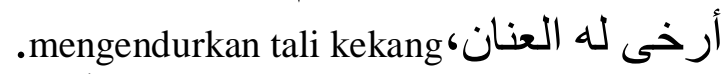
هـ فعل + اسم + حرف جر، مثل: أفضى الأمر به، menghasilkan... و - فعل + اسم + حرف جر + ال + اسم، مثل: أخذ طريقه إلى الرشد، .berjalan menuju keinsyafan ثالثا: تركيب جملة عابرة الذي يتألف من كلمنين أو أكثر، وله معنى

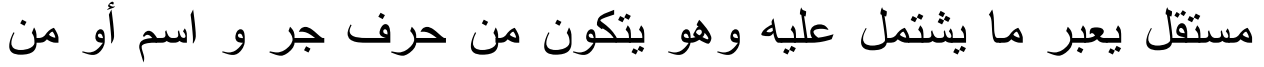

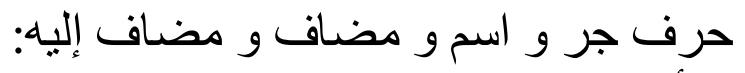

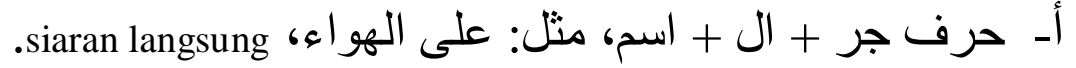

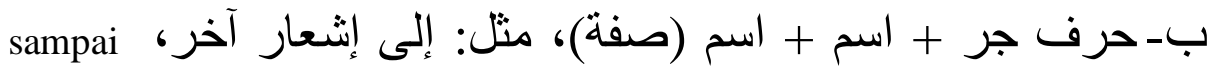
.dikeluarkannya pemberitahuan baru وتعتبر المتلازمات اللفظية من أهم عناصر الربط المسهمة في واني اتساق النصوص (Cohesion) وهي حروف العطف (Conjunction) و أسماء الإشارة (Demonstratives) و الأسماء الموصولة (Anaphor) و (Relative Pronouns) و الضمائر

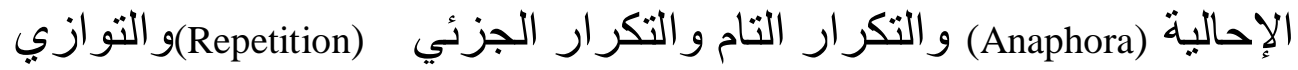

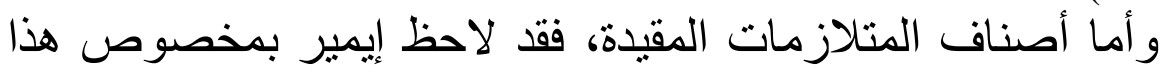
(Parallelism)

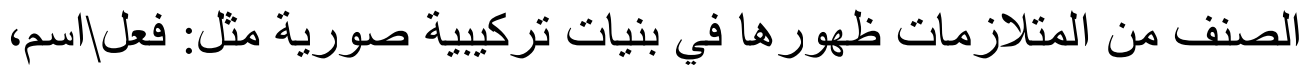
فعل|سم|فضلة، و اسم|صفة. و عليه تم تصنيفها في قاموس بي بي إي كمات كان

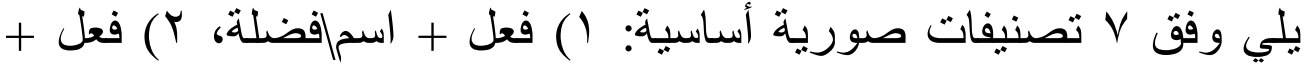

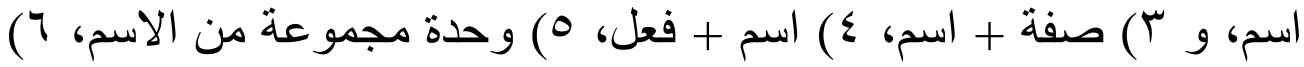

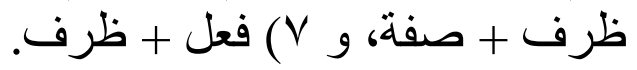
و إذا تتبعنا بعض النصوص العربية وفق تصنيف مبنيف

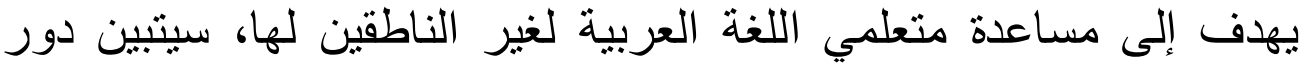


المعلومات النحوية و المعلومات الدلالية المرتبطة بأجز اء الخطاب التي ننوي

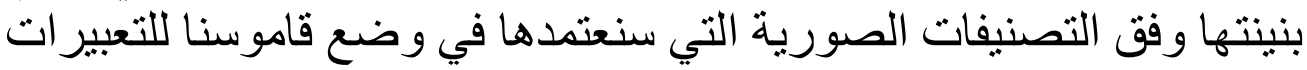
المتلازمة في اللغة العربية.

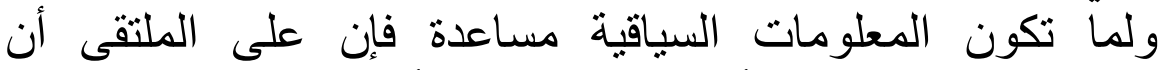

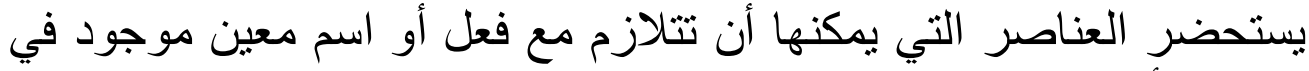

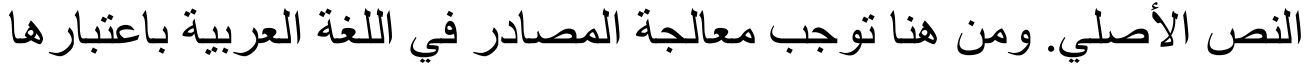

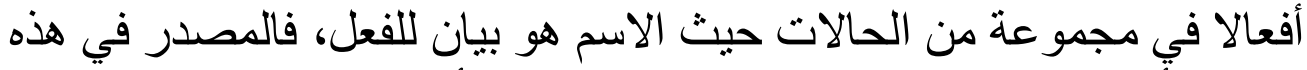

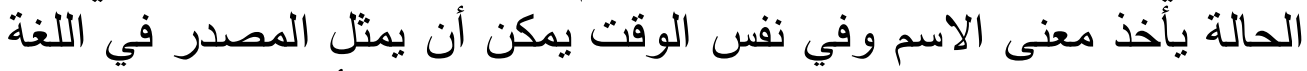

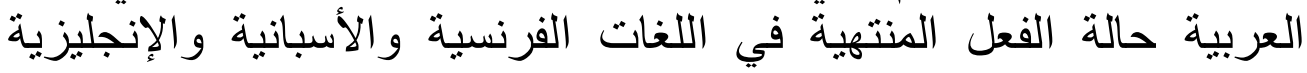

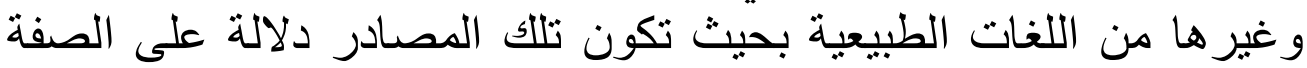
تعلى الفعل في نفس الوقت

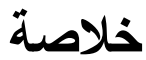

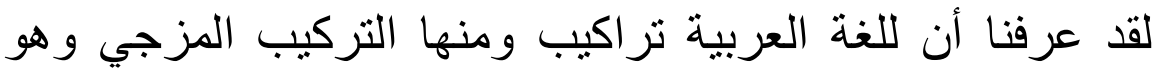
تركيب متكون من فعل و اسم منل حضر موت، ونركيب من اسم و اسم منل تئل

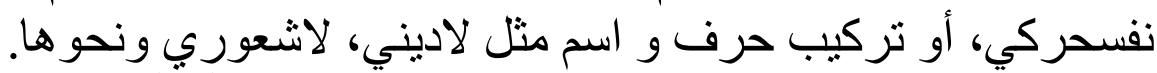
و المتلازمات اللفظية هي تركيب من كلمتين أو أكثر ولكن لئن يختلف

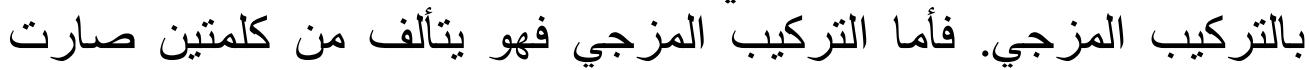

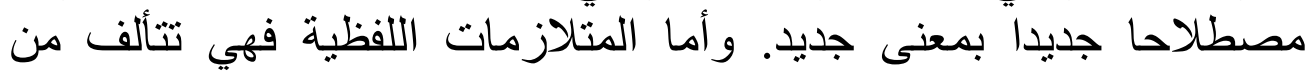

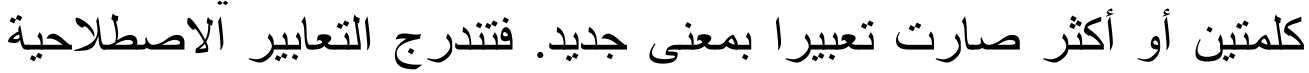
من المتلازمات اللفظية. فهذا الظرف بدل على أن اللغة أي لغة كانت ماز الت تنمو وتتطور

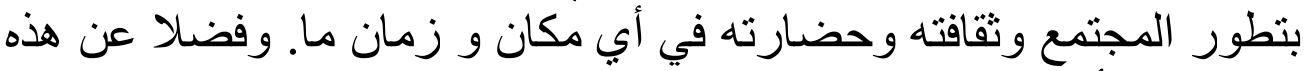
التغير ات تتأثر على معانى المفردات في اللغة العربية خاصة في في المعان في وفاجم. 


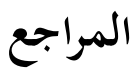

$$
\begin{aligned}
& \text { عبد الغني، عبد العظيم. 7 ج . . . مغهوم المتلازمات و إشكاليات الاشتغال المعجمي } \\
& \text { (في الدراسات المعجمية) (الرباط: الجمعية المغربية للدراسات المعجمية) }
\end{aligned}
$$

Firth, J.R. 19ז $\varepsilon_{-} 1901$. Papers In Linguistics (London: Oxford University Press)

Kamalie, Saifullah, Kolokosi Dalam Bahasa Arab: Apa, Mengapa dan Bagaimana?, قدمت المقالة في المؤتمر الدولي في اللغة العربية

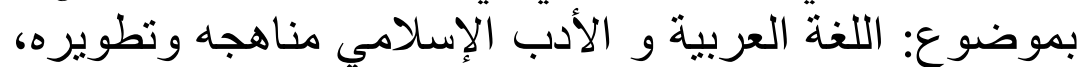

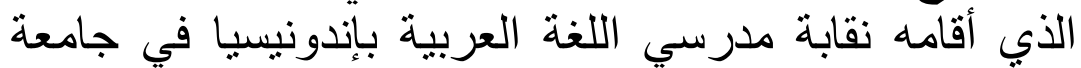

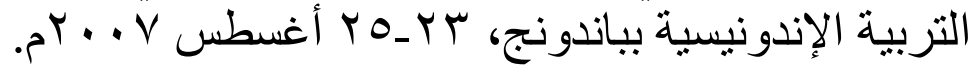

Maretta Kartika Sari, Kesalahan Unsur Leksikal (Jakarta: FIB UI, Y. . १)

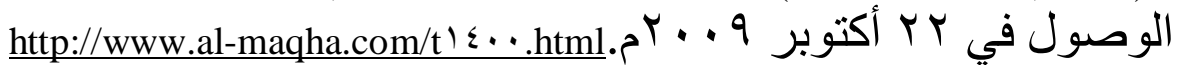

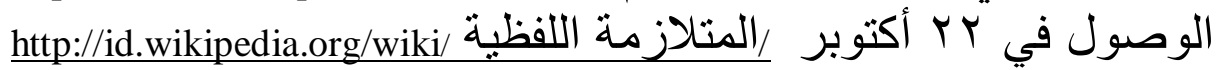
.$r^{r} \cdot 9$ 